\title{
Tumor necrosis factor-related apoptosis inducing ligand expression and activity in hen granulosa cells
}

\author{
A L Johnson, Christine Ratajczak, Morgan J Haugen, Han-Ken Liu and Dori C Woods \\ Department of Biological Sciences and the Walther Cancer Institute, The University of Notre Dame, PO Box 369, \\ Notre Dame, Indiana 46556, USA \\ Correspondence should be addressed to A L Johnson; Email: johnson.128@nd.edu
}

\begin{abstract}
Tumor necrosis factor-related apoptosis inducing ligand (TRAIL) represents one of several cytokine members of the tumor necrosis factor superfamily reported to initiate apoptosis in a wide range of transformed, but not most normal, cell types. The present studies were conducted to evaluate the potential for TRAIL to promote apoptotic cell death in differentiated granulosa cells collected from hen preovulatory follicles. While mRNA encoding critical components (including TRAIL) required for a functional extrinsic cell death pathway are expressed in granulosa cells, TRAIL treatment by itself fails to induce either caspase-3 activity or a decrease in cell viability. On the other hand, preculture of cells with the conventional chemotherapeutic, cisplatin, or the $20 S$ proteosome inhibitor, Z-LLF-CHO, sensitizes granulosa cells to TRAIL as evidenced by enhanced caspase-3 activity after $4 \mathrm{~h}$ of culture and loss of cell viability after $24 \mathrm{~h}$ when compared with either cisplatin or Z-LLF-CHO treatment alone. Moreover, the sensitizing effect of Z-LLF-CHO on TRAIL-induced loss of cell viability is prevented by the selective caspase-8 inhibitor, Z-IETD-FMK. Interestingly, TRAIL mRNA expression is elevated both in prehierarchal follicles undergoing spontaneous atresia and in prehierarchal follicles induced to undergo atresia for $6 \mathrm{~h}$ in vitro. In summary, the data demonstrate the presence of a functional TRAIL signaling pathway in hen granulosa cells, and are consistent with the possibility that TRAIL signaling may directly or indirectly participate in the process of follicle atresia in vivo.
\end{abstract}

Reproduction (2007) 133 609-616

\section{Introduction}

Tumor necrosis factor-related apoptosis inducing ligand (TRAIL) represents one of several members of the tumor necrosis factor superfamily (TNFSF) capable of initiating apoptosis in a wide range of cell types via the engagement of death domain-containing receptors (Bridgham et al. 2003, LeBlanc \& Ashkenazi 2003, Sheikh \& Huang 2004). Of particular interest are reports that TRAIL (TNFSF10) preferentially promotes apoptotic cell death in neoplastic cells, yet exhibits no, to comparatively low, toxicity in a wide variety of normal tissues (French \& Tachopp 1999, Walczak et al. 1999). While the actions of the TNF $\alpha / T N F R 1$ and Fas ligand/Fas systems in the normal ovary, and specifically within granulosa cells, have previously been described in some detail (e.g., Basini et al. 2002, Jiang et al. 2003, Chen et al. 2005, Margalit et al. 2005, Quirk et al. 2006), the ability of TRAIL to affect normal granulosa cell viability has received comparatively less attention. In the two somewhat conflicting publications to date, TRAIL has been reported to have little effect (Wada et al. 2002) or to induce caspase- 3 and apoptotic cell death (Inoue et al. 2003) in cultured granulosa cells collected from healthy porcine follicles.

In mammals, TRAIL signaling occurs primarily through two members from a large TNF receptor superfamily (TNFRSF), DR4 (TNFRSF10A) and DR5 (TNFRSF10B). When bound by TRAIL, the receptors form homotrimers, a process that modifies the conformation of the cytoplasmic domain to enable binding of the receptor death domain with the death domain (DD) of the cytoplasmic adaptor protein, Fas-associated death domain protein (FADD). In turn, FADD interacts with the initiator caspase, caspase-8, via a death effector domain (DED). Activated caspase-8 can cleave BH3-interacting domain death agonist (Bid) and processed Bid then initiates the release of mitochondrial cytochrome $c$ (cytC). The presence of cytosolic cytC initiates the intrinsic signaling pathway and promotes the formation of an apoptosome complex consisting of apoptosis protease activating factor-1 (APAF-1) and the intrinsic pathway initiator caspase, caspase-9. In turn, processed caspase-9, as well as caspase-8, activates the executioner caspase, 
caspase-3. These events ultimately promote a selfamplification of caspase activation that leads to cell death (reviewed in Locksley et al. 2001, Johnson \& Bridgham 2002).

On the other hand, the failure of TRAIL to kill normal cells, as well as the resistance to TRAIL in some tumor cells and transformed cell lines, is attributed to one or more antiapoptotic mechanisms. For instance, TRAIL-induced apoptosis has been shown to be attenuated or prevented in various tissues by decoy receptors (DcR), such as DcR1 (TNFRSF10C), DcR2 (TNFRSF10D), and osteoprotegrin (TNFRSF11B). Such DcRs lack an intracellular DD and are proposed to sequester and prevent TRAIL binding to DR4 or DR5 and/or interfere with receptor trimerization (Degli-Esposti et al. 1997a, 1997b, Emery et al. 1998). In mammalian granulosa cells, the expression of a variety of intracellular proteins, such as Fas-associated death domain-like interleukin-1 $\beta$-converting enzyme (FLICE)inhibiting protein ( $\mathrm{FLIP}_{\mathrm{L}}$; Xiao et al. 2002), anti-apoptotic Bcl-2 family members (e.g., Bcl-2 and Bcl-x; Tilly et al. 1995, Hsu et al. 1996), inhibitor of apoptosis proteins (IAPs; Xiao et al. 2001), and survivin (Kumazawa et al. 2005), can attenuate caspase activity and/or are associated with a reduced incidence of apoptosis.

Physiological factors that influence granulosa cell function during follicle development in the hen have been the subject of many investigations, as the granulosa layer is proposed to play a central role in regulating follicle viability and differentiation. In current studies, we utilize the hen ovary as a model system to study cell death pathways as a mechanism to influence ovarian follicle viability during follicle development (reviewed in Johnson 2003, Johnson \& Woods 2007). Evidence from hen granulosa cells has been provided both for the apoptosis initiated following activation of the intrinsic cell death pathway (Johnson \& Bridgham 2002), and for the attenuation of apoptosis via intracellular anti-apoptotic proteins, such as Bcl-x (Johnson et al. 1996, Johnson \& Bridgham 2002), the clAP1 ortholog, inhibitor of T-cell apoptosis (ITA) (Johnson et al. 1998), and survivin (Johnson et al. 2002). No less than four TNFRSF members that contain an intracellular DD are expressed by hen granulosa cells, including Fas (TNFRSF6; Bridgham \& Johnson 2001), TNFR1 (TNFRSF1; Bridgham \& Johnson 2001), TNFRSF23 (Bridgham \& Johnson 2004), and the putative ortholog to mammalian DR5 (TNFRSF10B; Bridgham \& Johnson 2002). Nevertheless, in the hen, only TNF $\alpha$ has been demonstrated thus far to induce granulosa cell death, and only in undifferentiated granulosa from prehierarchal follicles (Witty et al. 1996). Accordingly, in the present report, we provide evidence for (1) the expression of TRAIL mRNA in both normal and atretic hen ovarian follicles; (2) an intact extrinsic signaling pathway with the potential to mediate TRAIL-induced apoptosis in granulosa cells; and (3) the facilitation of granulosa cell apoptosis when TRAIL is co-cultured in vitro in conjunction with a conventional chemotherapeutic or a proteosome inhibitor.

\section{Materials and Methods}

\section{Animals and reagents}

Single-comb white leghorn hens ( $\mathrm{H} \& \mathrm{H}$ Poultry, Portland, IN, USA), 25-40 weeks of age, and laying regular sequences of at least five to six eggs, were used in all studies described. Birds were housed individually in laying batteries, provided with free access to feed (Purina Layeena Mash, Purina Mills, St Louis, MO, USA) and water, and were exposed to a photoperiod of $15 \mathrm{~h}$ light:9 h darkness, with lights on at midnight. Individual laying cycles were monitored by the daily timing of oviposition. Hens were killed approximately 16-18 h prior to a mid-sequence ovulation by cervical dislocation. All procedures described herein were reviewed and approved by the University of Notre Dame Institutional Animal Care and Use Committee, and were performed in accordance with the Guiding Principles for the Care and Use of Laboratory Animals.

Tissues collected for isolation of total RNA included ovarian stroma, post-ovulatory follicle, brain, spleen, bone marrow, oviduct, kidney, and heart. Ovarian follicle tissues included granulosa and theca from $3-5 \mathrm{~mm}$ to 6-8 $\mathrm{mm}$ diameter prehierarchal (prior to selection) follicles, the most recently selected 9-12 mm follicle, and the second largest (F2) and largest (F1) preovulatory follicle. Morphologically normal and atretic follicles (3-8 $\mathrm{mm}$ ) and comparably sized normal follicles induced to undergo atresia in vitro were processed without separating the granulosa and theca layers, as described previously (Bridgham \& Johnson 2002). Follicle atresia was verified by monitoring oligonucleosome formation (Johnson et al. 2001).

Human recombinant TRAIL, consisting of the soluble TNF-like extracellular domain (the C-terminal 168 amino acids of TRAIL), was obtained from PeproTech (Rocky Hill, NJ, USA). The $20 \mathrm{~S}$ proteosome inhibitor, Z-LLF$\mathrm{CHO}$, was from Calbiochem (San Diego, CA, USA), and the caspase-8 inhibitor, Z-IETD-FMK, was from R\&D Systems (Minneapolis, MN, USA). Cycloheximide and cisplatin (cis-platinum(II)-diammine dichloride) were purchased from Sigma Chemical.

\section{Amplification of receptor adaptor plus pro- and anti-apoptotic protein cDNAs}

In an initial effort to verify a functional TRAIL signaling pathway in normal granulosa cells, Gallus orthologs of mammalian TRAIL, receptor adaptor proteins (FADD and receptor-interacting protein (RIP)), an anti-apoptotic protein $\left(\mathrm{FLIP}_{\mathrm{L}}\right)$, two pro-apoptotic proteins (Bid and APAF-1), and caspase-8 and caspase-9 were amplified from reversed transcribed RNA (RT System, Promega) collected from ovarian stroma and granulosa cells from prehierarchal and preovulatory follicles. Accession numbers and primer pairs specific for the Gallus orthologs are provided in Table 1. Amplification 
Table 1 Primer pairs utilized for the amplification of Gallus TRAIL, TRAIL-like, receptor adaptor, caspase-8, and pro- and anti-apoptotic protein cDNAs.

\begin{tabular}{|c|c|c|c|}
\hline Product & Accession no. & Primer sequence $-5^{\prime}$ to $3^{\prime}$ & $\# \mathbf{n t}$ \\
\hline \multirow[t]{2}{*}{ TRAIL } & AB114678 & Forward: CAAAGACAGAGTGGCTGACCCC & 417 \\
\hline & & Reverse: ATTCGTTCCAACAAACCCGAG & \\
\hline \multirow[t]{2}{*}{ FADD } & ENSGALT-00000012340 & Forward: GGAAAAGGAAGTTGGAGTCTGTCC & 374 \\
\hline & & Reverse: TTTCTGCСАСТСТCGAAGCGAC & \\
\hline \multirow[t]{2}{*}{ RIP } & NM_204402 & Forward: GCTTTGGCATTGTAATCTGGGC & 573 \\
\hline & & Reverse: TTTCAGGGGTGTATGGTGGAAC & \\
\hline \multirow[t]{2}{*}{ FLIP $_{\mathrm{L}}$} & XM_421935 & Forward: CAAGGTTACAGAAGCACAGGAGTTG & 292 \\
\hline & & Reverse: AGGAATAGTGTCTTTCAAGGGCG & \\
\hline \multirow[t]{2}{*}{ Bid } & AY112660 & Forward: CTTCTGATCTGAAGCAGACC & 427 \\
\hline & & Reverse: AGACACCAGGTACTCCTCC & \\
\hline \multirow[t]{2}{*}{ APAF-1 } & XM_416167 & Forward: ACAGAATACACAGAAGGAGCGAGC & 562 \\
\hline & & Reverse: CAGCATCAGCAAACGAAGACG & \\
\hline \multirow[t]{2}{*}{ Caspase-8 } & AY057939 & Forward: GCCAATCACTTGCTGGAAAACC & 426 \\
\hline & & Reverse: ТСТСТGССТСТGСТСССАТTTAG & \\
\hline \multirow[t]{2}{*}{ Caspase-9 } & AY057940 & Forward: ACCCTGCGGAACCTCAAAGC & 453 \\
\hline & & Reverse: GGACACAAAACCTGGAAAAGTTG. & \\
\hline
\end{tabular}

The GenBank or expressed sequence tag (BBSRC ChickEST) Database (http://chick.umist.ac.uk/; Boardman et al. 2002) accession numbers plus predicted size of amplified product (nt) are provided.

conditions were specific for each primer pair, but included an initial denaturing for 3 min at $94{ }^{\circ} \mathrm{C}$ followed by 45 -s denaturing at $94{ }^{\circ} \mathrm{C}, 30$-s annealing at $51-62{ }^{\circ} \mathrm{C}$, depending upon primer pair, and 90 -s extension at $72{ }^{\circ} \mathrm{C}$ for 35 cycles using Taq DNA polymerase (Invitrogen). All PCR products were subsequently subcloned using the TOPO TA Cloning Kit for Sequencing (Invitrogen) and sequenced for verification of nucleic acid identity.

\section{Northern blot analysis}

EcoRI restriction digests were performed to isolate a 417 nt Gallus trail insert for use as cDNA probe templates. Templates were random prime labeled with the Megaprime DNA Labeling System (Amersham) and $\left[{ }^{32} \mathrm{P}\right] \mathrm{dCTP}$ (3000 Ci/mmol; Amersham). Prehybridization was carried out for at least $30 \mathrm{~min}$ at $60^{\circ} \mathrm{C}$, during which time probes were added and hybridization was allowed to proceed overnight. Stringent washes were conducted by rinsing with $2 \times$ SSC (single strength $\mathrm{SSC}=150 \mathrm{mM}$ sodium chloride and $15 \mathrm{mM}$ sodium citrate, $\mathrm{pH}$ 7.0) at room temperature, two 15-min washes in $2 \times$ SSC and $1 \%$ SDS at $60^{\circ} \mathrm{C}$, and one 15 -min wash with $0.1 \times$ SSC and $0.1 \%$ SDS at $60^{\circ} \mathrm{C}$, followed by exposure to phosphorimaging plates. Images were captured using the Storm 840 Phosphorlmager system equipped with the ImageQuant data reduction system (Molecular Dynamics, Sunnyvale, CA, USA). Blots were subsequently re-probed with chicken $18 \mathrm{~S}$ rRNA to standardize for loading of RNA (Bridgham \& Johnson 2001).

\section{Cell density assays}

Granulosa layers from F2 and F3 follicles were collected and cells were dispersed as described previously (Woods et al. 2005). Immediately following dispersion, $1.5 \times 10^{4}$ cells were seeded onto a 96-well plate. Cells were treated with or without TRAIL in the presence or absence of additional factors for $24 \mathrm{~h}$. All treatments in each replicate experiment were performed in triplicate. Cell density (a measure of metabolic activity and viability) was determined using the colorimetric CellTiter 96 Aqueous One Solution Cell Proliferation Assay (Promega). The indicator solution was added directly to the plate after 24-h culture, incubated for an additional $1-4 \mathrm{~h}$, and the absorbance values were read at $490 \mathrm{~nm}$.

\section{Caspase-3 activity assays}

Granulosa cells $\left(1.5 \times 10^{4}\right.$ cells $)$ from F2 and F3 follicles were seeded onto triplicate wells of clear bottom, black 96-well Costar plates (Corning, Inc., Corning, NY, USA), pretreated in the absence or presence of cisplatin $(10 \mu \mathrm{M})$ or Z-LLF-CHO $(10 \mu \mathrm{M})$ for $1 \mathrm{~h}$, and then cultured for an additional $4 \mathrm{~h}$ in the presence or absence of TRAIL $(100 \mathrm{ng} / \mathrm{ml})$. Caspase-3 activity was measured using the Apo-ONE Homogeneous Caspase-3 assay as recommended by the manufacturer (Promega). Fluorescence activity was monitored using excitation wavelength of $490 \mathrm{~nm}$ and emission wavelength of $525 \mathrm{~nm}$.

\section{Data analysis}

Experiments were independently replicated a minimum of three times unless otherwise specified. Standardized values for the combined replicate experiments were expressed as a fold difference (mean \pm s.E.M.) versus cultured control cells. Data were analyzed by one-way ANOVA without including data from the control group (arbitrarily set to 1.0), and the Fisher's protected least significant difference multiple range test for post hoc analysis. In instances where a Student's $t$-test was used to compare two related treatments, individual comparisons were made using original (non-transformed) data. 


\section{Results}

Gallus TRAIL mRNA is expressed in a variety of tissues within the mature hen (Fig. 1A). Within the ovary, levels of TRAIL mRNA are the highest in undifferentiated granulosa cells collected from 3 to $5 \mathrm{~mm}$ prehierarchal follicles, and decrease to the lowest levels subsequent to follicle selection (Fig. 1B). By comparison, theca layer levels of TRAIL mRNA do not change significantly during follicle development. Levels of expression are increased in prehierarchal follicles undergoing spontaneous atresia, when compared with normal follicles, and are also increased in follicles induced to undergo atresia following $6 \mathrm{~h}$ of incubation in vitro (Fig. 2).

RT and PCR amplification revealed ovarian expression of mRNA encoding two death receptor adaptor proteins (FADD and RIP), the anti-apoptotic protein, FLIP $\mathrm{L}_{\mathrm{L}}$ two pro-apoptotic proteins (Bid and APAF-1), and caspases associated with the extrinsic and intrinsic cell death pathways (caspase-8 and caspase-9, respectively; Fig. 3). Each is expressed in ovarian stromal tissue plus
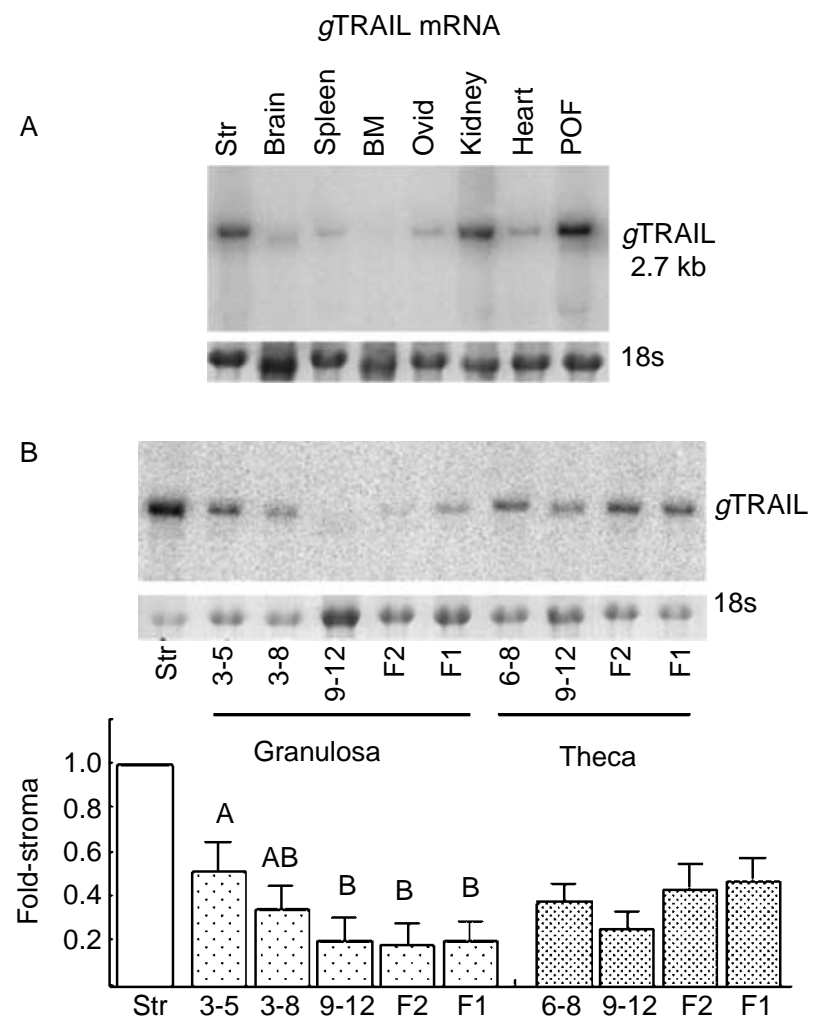

Figure 1 (A) Expression of Gallus (g) TRAIL mRNA in various tissues of the reproductively active hen by northern blot analysis. Str, ovarian stromal tissue; BM, bone marrow; Ovid, oviduct; POF, post-ovulatory follicle. $18 \mathrm{~S}$ rRNA is provided as a loading control. (B) Northern blot expression of TRAIL in granulosa and theca tissue of ovarian follicles during development, expressed relative to Str tissue. 3-5, 6-8, diameter $(\mathrm{mm})$ of prehierarchal follicle; 9-12, diameter $(\mathrm{mm})$ of most recently selected follicle; F2, F1, second largest and largest preovulatory follicle, respectively. A and B: $P<0.05$ from three replicate sets of tissues.
A

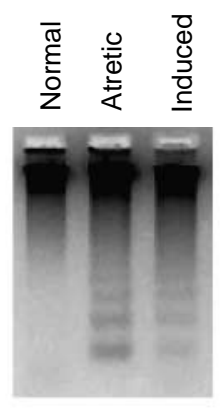

B

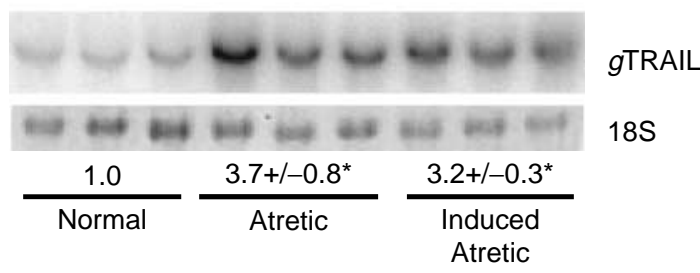

Figure 2 (A) Oligonucleosome formation in atretic prehierarchal (3-8 mm) follicles and in prehierarchal follicles induced to become atretic by a 6 -h incubation in vitro when compared with healthy prehierarchal follicles. (B) Northern blot analysis of TRAIL mRNA levels in normal, spontaneously atretic and induced atretic prehierarchal follicles. Fold increase when compared with normal follicles ( \pm s.E.M.) is shown at the bottom of each blot. ${ }^{*} P<0.05$ when compared with normal follicles, by Student's $t$-test.

undifferentiated granulosa cells from prehierarchal follicles and differentiated granulosa from preovulatory follicles.

Cell density assays were utilized to evaluate the effect of TRAIL treatment, added alone or in combination with additional agents, on the number of viable cells. In
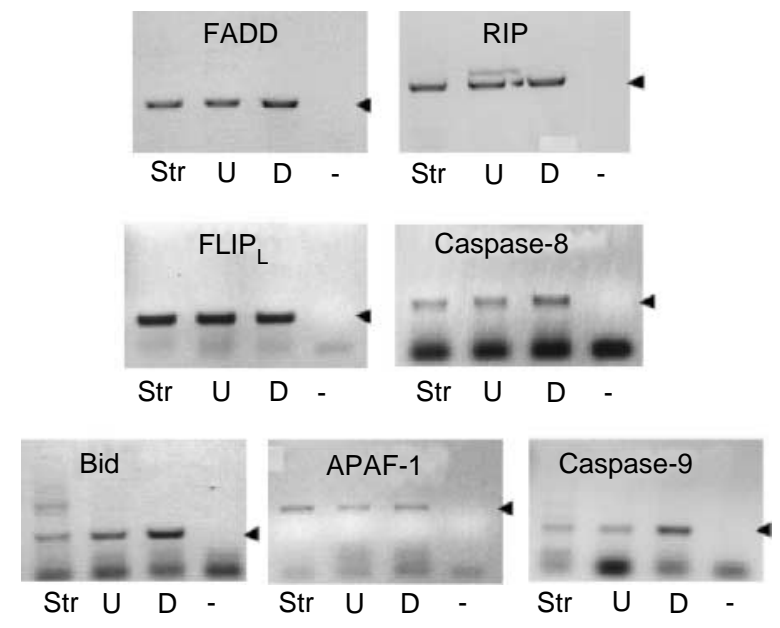

Figure 3 Amplification of cDNAs corresponding to TNFRSF adaptor proteins (FADD and RIP), extrinsic pathway proteins (anti-apoptotic protein, FLIP $_{\mathrm{L}}$, and caspase-8), and intrinsic pathway pro-apoptotic proteins (Bid, APAF-1, and caspase-9) expressed in undifferentiated (U) granulosa cells from 6 to $8 \mathrm{~mm}$ follicles and differentiated (D) granulosa from preovulatory follicles (arrow heads). Bottom bands represent primer dimers. Ovarian stromal tissue (Str) is included as a reference tissue. - , negative control (no template). 
differentiated granulosa cells, TRAIL treatment alone for $24 \mathrm{~h}$ had no significant effect on cell density when compared with control cultured cells (Figs 4 and 5). Not unexpectedly, treatment with cisplatin decreased the number of viable cells, but more importantly facilitated a further decrease in the number of viable cells when co-treated with TRAIL (Fig. 4). By comparison, co-culture of TRAIL in the presence of cycloheximide failed to significantly alter cell viability when compared with treatment with cycloheximide alone.

In addition, treatment of differentiated granulosa cells with the 20S proteosome inhibitor, Z-LLF-CHO $(10 \mu \mathrm{M})$, for $24 \mathrm{~h}$ reduced cell density in a dose-related fashion, and at each dose this reduction was enhanced by the presence of TRAIL (Fig. 5A). Importantly, while the caspase-8 inhibitor, Z-IETD-FMK $(10 \mu \mathrm{M})$, did not alter the actions of Z-LLF-CHO, this inhibitor prevented the reduction in viable cells observed when TRAIL was co-cultured with Z-LLF-CHO (Fig. 5B).

Finally, TRAIL treatment did not alter caspase-3 activity when compared with control cultured cells after a 4-h culture. However, caspase-3 activity was dramatically elevated in TRAIL-treated cells precultured in the presence, when compared with absence, of Z-LLF$\mathrm{CHO}$ or cisplatin (Fig. 6).

\section{Discussion}

The results reported herein demonstrate that despite the expression of mRNA encoding key signaling components that comprise an extrinsic cell death pathway (Fig. 7), differentiated granulosa from preovulatory follicles are normally resistant to TRAIL-induced apoptosis in vitro. Nevertheless, activation of TRAIL signaling via a functional extrinsic pathway and TRAIL-induced apoptosis can be elicited following co-treatment with either a conventional chemotherapeutic (cisplatin) or a pharmacologic inhibitor of proteosome activity (Z-LLF-CHO).

The characterization of Gallus TRAIL as well as PCR amplification of TRAIL in various tissues from the

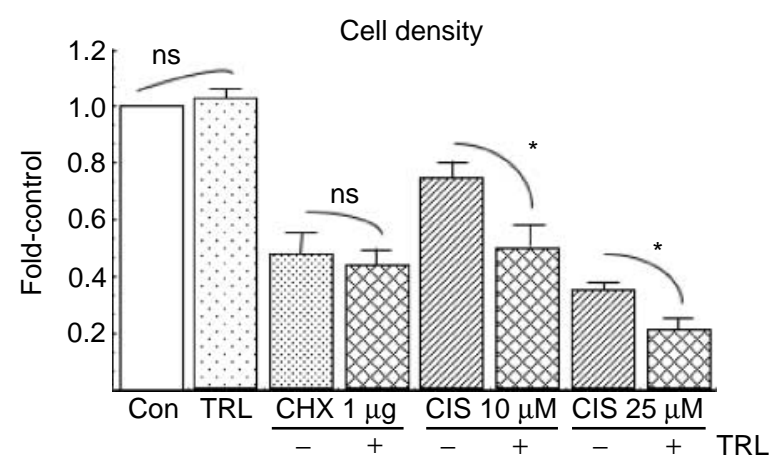

Figure 4 Analysis of cell density in differentiated granulosa cells from preovulatory follicles after treatment with TRAIL (TRL; $100 \mathrm{ng} / \mathrm{ml}$ ) in the presence or absence of cycloheximide (CHX) or cisplatin (CIS). Con, control cultured cells. ns, $P>0.05 ;{ }^{*} P<0.05$, by $t$-test.
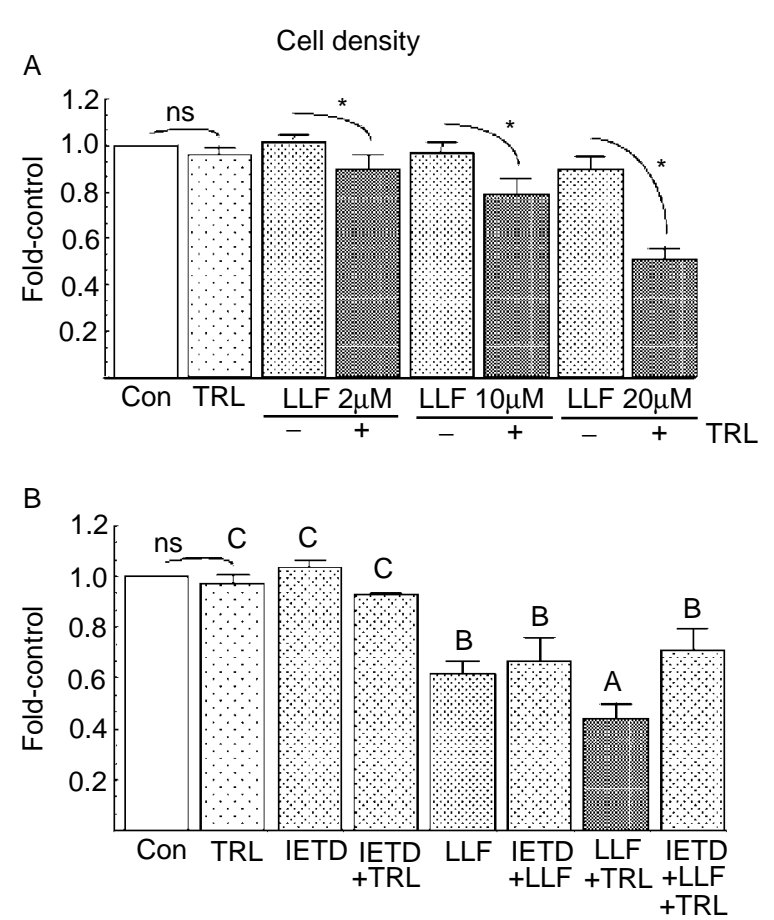

Figure 5 (A) Cell density analyses of differentiated granulosa cells after treatment with TRAIL (TRL; $100 \mathrm{ng} / \mathrm{ml}$ ) in the presence or absence of the $20 S$ proteosome inhibitor, Z-LLF-CHO (LLF). Con, control cultured cells. ns, $P>0.05 ;{ }^{*} P, 0.05$ by $t$-test. (B) Cell density measured following treatment with TRL with or without LLF $(10 \mu \mathrm{M})$ in the absence or presence of the caspase-8 inhibitor, Z-IETD-FMK (IETD; $10 \mu \mathrm{M})$. A-C: $P<0.05$ by ANOVA; ns, $P>0.05$ by $t$-test.

immature leghorn chicken plus several established chicken cell lines has previously been reported (Abdalla et al. 2004), yet apparently no evidence of functional TRAIL signaling in the chicken has been established. Similar to this previously published report, the use of northern blot analysis in the present study demonstrated that TRAIL mRNA is widely expressed within diverse tissues from the adult hen, and in particular, within developing ovarian follicles (Fig. 1). The relatively constant expression of TRAIL mRNA in the theca layer

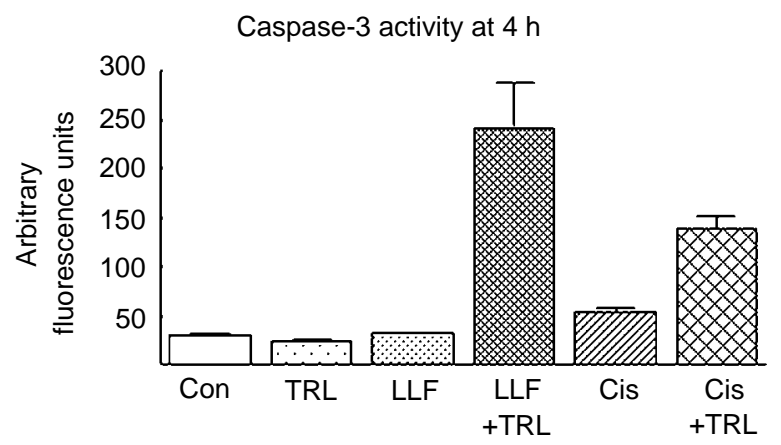

Figure 6 Representative assay (conducted with triplicate wells) of caspase-3 activity in differentiated granulosa cells after a $1-\mathrm{h}$ preculture without or with Z-LLF-CHO (LLF; $10 \mu \mathrm{M})$ or cisplatin (Cis; $10 \mu \mathrm{M})$ followed by a 4-h culture with or without TRAIL (100 ng/ml). This experiment was conducted two additional times with similar results. 


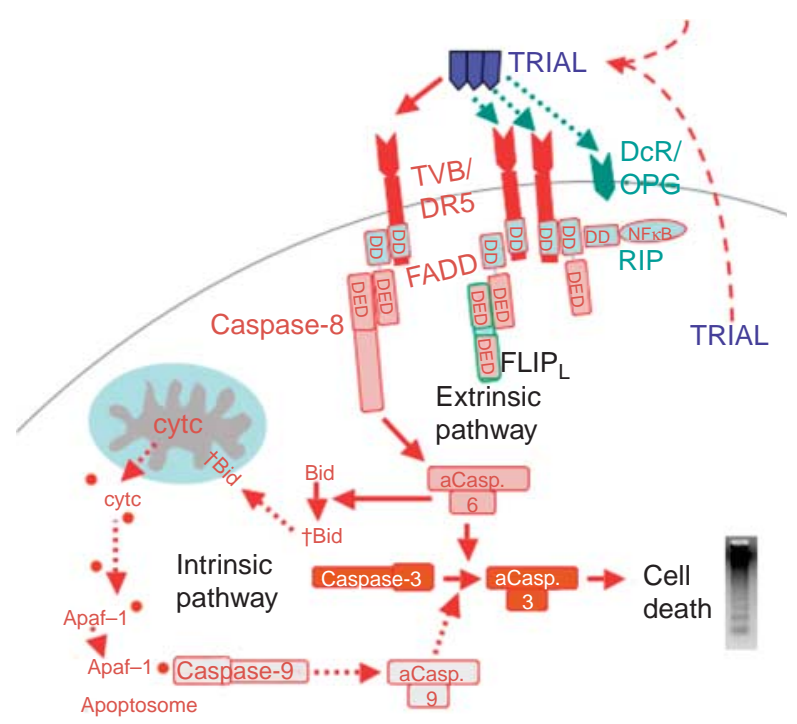

Figure 7 Proposed pathway for TRAIL signaling in hen granulosa cells. Solid arrows depict activation of the extrinsic pathway via the putative Gallus ortholog to DR5 (TVB; Bridgham \& Johnson 2002). Red dotted arrows depict the predicted activation of the intrinsic pathway based upon the demonstrated expression of APAF- 1 and caspase- 9 mRNA in granulosa cells from both prehierarchal and preovulatory follicles. Dotted green arrows predict potential pathways by which TRAILinduced apoptotsis is prevented, possibly via $\mathrm{FLIP}_{\mathrm{L}}$ or decoy receptors $(\mathrm{DcR})$, including osteoprotegerin (OPG; Bridgham \& Johnson 2003). In addition, the potential exists for TRAIL to activate the receptor adaptor protein, RIP. Because TRAIL mRNA is normally expressed within ovarian stromal, thecal, and granulosa tissues, it is predicted that TRAIL can act on granulosa cells in a paracrine and/or autocrine fashion (dashed lines). aCasp., activated caspase; DD, death domain; DED, death effector domain; tBid, truncated Bid. See text for additional details.

and the decreasing levels of expression within the granulosa layer during follicle development suggest that TRAIL has the potential to influence granulosa cell function in a paracrine and/or autocrine fashion. Nevertheless, as has previously been found for a number of primary cultured cells from mammals (reviewed by $\mathrm{Di}$ Pietro \& Zauli 2004), treatment of hen granulosa cells with TRAIL failed to promote apoptosis, as evidenced by the absence of TRAIL-induced caspase-3 activity after $4 \mathrm{~h}$ of culture (Fig. 6) and the similar density of metabolically active cells after $24 \mathrm{~h}$ (Fig. 5) when compared with control cultured cells.

Based upon limited evidence from hen granulosa cells for the ability of TNFSF ligands (other than TNF $\alpha$; Witty et al. 1996) to induce apoptosis via an extrinsic cell death pathway, we first sought to establish whether the intracellular adaptor and executioner genes normally required for TRAIL signaling are expressed. In fact, cDNAs representing critical adaptor proteins, pro- and anti-apoptotic proteins, and caspases were amplified from both undifferentiated granulosa cells from prehierarchal follicles and differentiated granulosa from preovulatory follicles, and are demonstrated for the first time to be expressed in the hen ovary (Fig. 3). In addition, the ability of soluble TRAIL to enhance cisplatin- and Z-LLF-CHOinduced caspase- 3 activity and the loss of cell viability provides evidence for a functional TRAIL death receptor. While TVB has previously been proposed to represent the Gallus ortholog to DR5 (Bridgham \& Johnson 2002), an ortholog to mammalian DR4 has yet to be identified. Combined with the previously described executioner caspase, caspase-3 (Johnson \& Bridgham 2000), as well as the TRAIL decoy receptor, osteoprotegerin (Bridgham \& Johnson 2003), the collective expression of these signaling components provides evidence for a functional and regulated extrinsic signaling pathway.

Significantly, treatment of hen granulosa cells with TRAIL in the presence of cisplatin or the proteosome inhibitor, Z-LLF-CHO, decreases the number of viable cells when compared with treatment each pharmacologic agent alone. That this additive effect can be attributed to the effects of the extrinsic pathway induced by TRAIL signaling is indicated by the ability of the selective caspase-8 inhibitor, Z-IETD-FMK, to prevent this decrease in cell viability (Fig. 5). Of relevance is a recent study using thoracic cancer cells that documented the importance of the intrinsic pathway, via mitochondrial- and caspase-9mediated amplification of caspase-8, as a critical component for TRAIL's additive actions (Nguyen et al. 2006).

An additive effect of TRAIL treatment on cisplatininduced cell death has previously been observed in human ovarian carcinoma cell lines (Siervo-Sassi et al. 2003, Liu et al. 2006). This effect has been associated with gene up-regulation of TRAIL receptor by cisplatin, and up-regulation of pro-apoptotic Bad and Bax plus a down-regulation of anti-apoptotic $\mathrm{BCl}-2$ and $\mathrm{BCl}$-x genes by TRAIL. Inhibition of proteosome activity has also been reported to sensitize ovarian epithelial cancer cell lines to TRAIL treatment, at least in part, by enhancing the accumulation of mature caspase-3 fragments (Lane et al. 2006). In the present studies, activity of the executioner caspase, caspase-3, was at most marginally enhanced by cisplatin or Z-LLF-CHO after a total of $5 \mathrm{~h}$ in culture (Fig. 6). By comparison, co-culture with TRAIL for $4 \mathrm{~h}$ dramatically enhanced caspase-3 activity in the presence of both cisplatin and Z-LLF-CHO. This enhanced caspase-3 activity is consistent with a sensitization of cells to TRAIL-induced activation of the initiator caspase, caspase-8, promoted by cisplatin and Z-LLF-CHO. By comparison, previous studies using rat or mouse granulosa cells have determined that cycloheximide potentiates Fas- and TNF $\alpha$-mediated cell death, presumably by preventing translation of antiapoptotic proteins, such as FLIP and X-linked IAP (Quirk et al. 1998, Xiao et al. 2001, 2002). The present study failed to suggest a cycloheximide-sensitive component to TRAIL-mediated cell death in hen granulosa within the 24-h culture period utilized (Fig. 4). This result suggests that cisplatin- and Z-LLF-CHO-mediated sensitization entails one or more post-translational events. 
Whereas primary cultured granulosa cells are normally resistant to TRAIL-induced apoptosis, it was observed that TRAIL mRNA is elevated in follicles undergoing atresia in vivo (Fig. 2). This latter observation is similar to that made in porcine granulosa cells collected from both early and more advanced atretic follicles (Inoue et al. 2003). Moreover, hen prehierarchal follicles induced to become atretic in vitro demonstrated elevated levels of TRAIL mRNA within $6 \mathrm{~h}$ when compared with freshly collected, healthy follicles. It has previously been established that the oligonucleosome formation characteristic of follicle atresia is associated with a rapid (within $2 \mathrm{~h}$ ) increase in caspase-3 activity (Johnson \& Bridgham 2000). While neither a cause-effect relationship with regard to atresia nor the signal(s) responsible for this induced TRAIL expression has been established herein or in porcine granulosa cells (Wada et al. 2002, Inoue et al. 2003), it remains possible that increased TRAIL expression is an early marker of follicle atresia, and that TRAIL-induced activation of the extrinsic pathway may directly or indirectly participate in the process of atresia in vivo.

Finally, there is an increasing number of reports from a variety of cell types that TRAIL can promote biological effects other than apoptotic cell death, including pro-survival, cell proliferation, and cell migration actions (Di Pietro \& Zauli 2004). During our search for receptor adaptor proteins associated with TRAIL signaling, we identified a Gallus ortholog to the death domain kinase, RIP, that is expressed in both undifferentiated and differentiated granulosa (Fig. 3). This Gallus adaptor protein contains a conserved DD capable of homodimerizing with the TRAIL receptor DD, as well as a conserved caspase- 8 cleavage site $\left(\mathrm{L}^{320} \mathrm{Q}^{321} \mathrm{~L}^{322} \mathrm{D}^{323}\right)$ that predicts its proteolytic cleavage to an inactive form by activated caspase-8. Significantly, RIP is not involved in TRAILinduced apoptotic cell death, but is essential for activation of NF- $\mathrm{BB}$ and Jun $\mathrm{N}$-terminal kinase (JNK) via a serine/threonine protein kinase domain (Lin et al. 2000). In rat granulosa cells, TNF-induced NF- $\mathrm{KB}$ signaling has been linked to cell survival via its ability to up-regulate FLIP (Xiao et al. 2002), while TNF-mediated cell proliferation is reported to be dependent upon JNK activity (Son et al. 2004). Based upon the inability of TRAIL treatment by itself to initiate caspase-3 activity (Fig. 6) or to negatively impact cell density (Figs 4 and 5) in primary cultured hen granulosa cells, it is predicted that an alternative action of TRAIL in these cells could be related to cell cycle progression and/or cell survival.

In summary, the present studies demonstrate that despite the presence of a functional extrinsic signaling pathway, differentiated hen granulosa cells are normally resistant to TRAIL-induced cell death. On the other hand, evidence that TRAIL mRNA expression is increased both in both hen and porcine follicles early during atresia provides the possibility that TRAIL may participate in this process. Cellular mechanisms responsible for both TRAIL resistance and induced sensitivity in hen granulosa cells are currently under investigation.

\section{Acknowledgements}

The authors acknowledge Dr Jamie Bridgham for contributions to the early portions of this work, Sara Barton and Martin Vonau for technical assistance, and Dr Neil Lobo for help with nucleic acid sequencing. This work was supported by grants from the Department of Defense (DAMD17-03-1-0206) and the National Science Foundation (IOB 04-45949) to A L Johnson. $\mathrm{H}-\mathrm{K}$ Liu was supported by the University of Notre Dame Walther Cancer Institute. The authors declare that there is no conflict of interest that would prejudice the impartiality of this scientific work.

\section{References}

Abdalla SA, Horiuchi H, Furusawa S \& Matsuda H 2004 Molecular cloning and characterization of chicken tumor necrosis factor (TNF)superfamily ligands, CD30L and TNF-related apoptosis inducing ligand (TRAIL). Journal of Veterinary Medical Science 66 643-650.

Basini G, Mainardi GL, Bussolati S \& Tamanini C 2002 Steroidogenesis, proliferation and apoptosis in bovine granulosa cells: role of tumour necrosis factor-alpha and its possible signalling mechanisms. Reproduction, Fertility, and Development 14 141-150.

Boardman PE, Sanz-Ezquerro J, Overton JM, Burt DW, Bosch E, Fong WT, Tickle C, Brown WR, Wilson SA \& Hubbard SJ 2002 A comprehensive collection of chicken cDNAs. Current Biology 12 1965-1969.

Bridgham JT \& Johnson AL 2001 Expression and regulation of Fas antigen and tumor necrosis factor receptor type I in hen granulosa cells. Biology of Reproduction 65 733-739.

Bridgham JT \& Johnson AL 2002 Avian TVB (DR5-like) death receptor expression in hen ovarian follicles. Biochemical and Biophysical Research Communications 291 226-232.

Bridgham JT \& Johnson AL 2003 Characterization of chicken TNFR suoerfamily decoy receptors, DcR3 and osteoprotegerin. Biochemical and Biophysical Research Communications 307 956-961.

Bridgham JT \& Johnson AL 2004 Alternatively spliced variants of Gallus gallus TNFRSF23 are expressed in the ovary and differentially regulated by cell signaling pathways. Biology of Reproduction $\mathbf{7 0}$ 972-979.

Bridgham JT, Wilder JA, Hollocher H \& Johnson AL 2003 All in the family: evolutionary and functional relationships among vertebrate death receptors. Cell Death and Differentiation 10 19-25.

Chen Q, Yano T, Matsumi H, Osuga Y, Yano N, Xu J, Wada O, Koga K, Fujiwara T, Kugu K \& Taketani Y 2005 Cross-talk between Fas/Fas ligand system and nitric oxide in the pathway subserving granulosa cell apoptosis: a possible regulatory mechanism for ovarian follicle atresia. Endocrinology 146 808-815.

Degli-Esposti MA, Dougall WC, Smolak PJ, Waugh JY, Smith CA \& Goodwin RG 1997a The novel receptor TRAIL-R4 induces NF-kappaB and protects against TRAIL-mediated apoptosis, yet retains an incomplete death domain. Immunity 7 813-820.

Degli-Esposti MA, Smolak PJ, Walczak H, Waugh J, Huang CP, DuBose RF, Goodwin RG \& Smith CA 1997b Cloning and characterization of TRAIL-R3, a novel member of the emerging TRAIL receptor family. Journal of Experimental Medicine $\mathbf{1 8 6}$ 1165-1170.

Di Pietro R \& Zauli G 2004 Emerging non-apoptotic functions of tumor necrosis factor-related apoptosis-inducing ligand (TRAIL)/Apo2L. Journal of Cellular Physiology 201 331-340. 
Emery JG, McDonnell P, Burke MB, Deen KC, Lyn S, Silverman C, Dul E, Appelbaum ER, Eichman C, DiPrinzio R, Dodds RA, James IE, Rosenberg M, Lee JC \& Young PR 1998 Osteoprotegerin is a receptor for the cytotoxic ligand TRAIL. Journal of Biological Chemistry 273 14363-14367.

French LE \& Tachopp J 1999 The TRAIL to selective tumor death. Nature Medicine 5 146-147.

Hsu SY, Lai RJ, Finegold M \& Hsueh AJ 1996 Targeted overexpression of $\mathrm{Bcl}-2$ in ovaries of transgenic mice leads to decreased follicle apoptosis, enhanced folliculogenesis, and increased germ cell tumorigenesis. Endocrinology 137 4837-4843.

Inoue N, Manabe N, Matsui T, Maeda A, Nakagawa S, Wada S \& Miyamoto H 2003 Roles of tumor necrosis factor-related apoptosisinducing ligand signaling pathway in granulosa cell apoptosis during atresia in pig ovaries. Journal of Reproduction and Development 49 313-321.

Jiang JY, Cheung CK, Wang Y \& Tsang BK 2003 Regulation of cell death and cell survival gene expression during ovarian follicular development and atresia. Frontiers in Bioscience 8 222-237.

Johnson AL 2003 Intracellular mechanisms regulating cell survival in ovarian follicles. Animal Reproduction Science 78 185-201.

Johnson AL \& Bridgham JT 2000 Caspase-3 and -6 expression and enzyme activity in hen granulosa cells. Biology of Reproduction 62 589-598.

Johnson AL \& Bridgham JT 2002 Caspase-mediated apoptosis in the vertebrate ovary. Reproduction 124 19-27.

Johnson AL \& Woods DC 2007 Ovarian dynamics and follicle development. In Reproductive Biology and Phylogeny of Aves, pp 243-277. Ed. BGM Jamieson. Plymouth, UK: Science Publishers, Inc (ch 6).

Johnson AL, Bridgham JT, Witty JP \& Tilly JL 1996 Susceptibility of avian ovarian granulosa cells to apoptosis is dependent upon stage of follicle development and is related to endogenous levels of bcl-xlong gene expression. Endocrinology 137 2059-2066.

Johnson AL, Bridgham JT, Digby MR \& Lowenthal JW 1998 Expression of the inhibitor of T-cell apoptosis (ita) gene in hen ovarian follicles during development. Biology of Reproduction 58 414-420.

Johnson AL, Bridgham JT \& Swenson JA 2001 Activation of the Akt/protein kinase B signaling pathway is associated with granulosa cell survival. Biology of Reproduction 64 1566-1574.

Johnson AL, Langer JS \& Bridgham JT 2002 Survivin as a cell cyclerelated and antiapoptotic protein in granulosa cells. Endocrinology 143 3405-3413.

Kumazawa Y, Kawamura K, Sato T, Sato N, Konishi Y, Shimizu Y, Fukuda J, Kodama H \& Tanaka T 2005 HCG up-regulates survivin mRNA in human granulosa cells. Molecular Human Reproduction 11 161-166.

Lane D, Cote M, Grondin R, Couture MC \& Piche A 2006 Acquired resistance to TRAIL-induced apoptosis in human ovarian cancer cells is conferred by increased turnover of mature caspase- 3 . Molecular Cancer Therapeutics 5 509-521.

LeBlanc HN \& Ashkenazi A 2003 Apo2L/TRAIL and its death and decoy receptors. Cell Death and Differentiation 10 66-75.

Lin Y, Devin A, Cook A, Keane MM, Kelliher M, Lipkowitz S \& Liu ZG 2000 The death domain kinase RIP is essential for TRAIL (Apo2L)induced activation of IkappaB kinase and c-Jun N-terminal kinase. Molecular and Cellular Biology 20 6638-6645.

Liu P, Mao H \& Hou P 2006 Synergistic antitumor effect of tumor necrosis factor-related apoptosis-inducing ligand combined with cisplatin in ovarian carcinoma cell lines in vitro and in vivo. International Journal of Gynecological Cancer 16 538-548.
Locksley RM, Killeen N \& Lenardo MJ 2001 The TNF and TNF receptor superfamilies: integrating mammalian biology. Cell 104 487-501.

Margalit KA, Cowan RG, Harman RM \& Quirk SM 2005 Apoptosis of bovine ovarian surface epithelial cells by Fas antigen/Fas ligand signaling. Reproduction 130 751-758.

Nguyen DM, Yeow WS, Ziauddin MF, Baras A, Tsai W, Reddy RM, Chua A, Cole GW Jr \& Schrump DS 2006 The essential role of the mitochondria-dependent death-signaling cascade in chemotherapyinduced potentiation of Apo2L/TRAIL cytotoxicity in cultured thoracic cancer cells: amplified caspase 8 is indispensable for combinationmediated massive cell death. Cancer Journal 12 257-273.

Quirk SM, Porter DA, Huber SC \& Cowan RG 1998 Potentiation of Fasmediated apoptosis of murine granulosa cells by interferon-gamma, tumor necrosis factor-alpha, and cycloheximide. Endocrinology 139 4860-4869.

Quirk SM, Cowan RG \& Harman RM 2006 The susceptibility of granulosa cells to apoptosis is influenced by oestradiol and the cell cycle. Journal of Endocrinology 189 441-453.

Sheikh MS \& Huang Y 2004 Death receptors as targets of cancer therapeutics. Current Cancer Drug Targets 4 97-104.

Siervo-Sassi RR, Marrangoni AM, Feng X, Naoumova N, Winans M, Edwards RP \& Lokshin A 2003 Physiological and molecular effects of Apo2L/TRAIL and cisplatin in ovarian carcinoma cell lines. Cancer Letters 190 61-72.

Son DS, Arai KY, Roby KF \& Terranova PF 2004 Tumor necrosis factor alpha (TNF) increases granulosa cell proliferation: dependence on c-Jun and TNF receptor type 1. Endocrinology 145 1218-1226.

Tilly JL, Tilly KI, Kenton ML \& Johnson AL 1995 Expression of members of the $b c l-2$ gene family in the immature rat ovary: equine chorionic gonadotropin-mediated inhibition of granulosa cell apoptosis is associated with decreased bax and constitutive bcl-2 and bcl-xlong messenger ribonucleic acid levels. Endocrinology 136 232-241.

Wada S, Manabe N, Inoue N, Nakayama M, Matsui T \& Miyamoto H 2002 TRAIL-decoy receptor-1 disappears in granulosa cells of atretic follicles in porcine ovaries. Journal of Reproduction and Development 48 167-173.

Walczak H, Miller RE, Ariail K, Gliniak B, Griffith TS, Kubin M, Chin W, Jones J, Woodward A, Le T, Smith C, Smolak P, Goodwin RG, Rauch CT, Schuh JC \& Lynch DH 1999 Tumoricidal activity of tumor necrosis factor-related apoptosis-inducing ligand in vivo. Nature Medicine 5 157-163.

Witty JP, Bridgham JT \& Johnson AL 1996 Induction of apoptotic cell death in hen granulosa cells by ceramide. Endocrinology 137 $5269-5277$.

Woods DC, Haugen MJ \& Johnson AL 2005 Opposing actions of TGF $\beta$ and MAP kinase signaling in undifferentiated hen granulosa cells. Biochemical and Biophysical Research Communications 336 450-457.

Xiao CW, Ash K \& Tsang BK 2001 Nuclear factor-kappaB-mediated $\mathrm{X}$-linked inhibitor of apoptosis protein expression prevents rat granulosa cells from tumor necrosis factor alpha-induced apoptosis. Endocrinology 142 557-563.

Xiao CW, Asselin E \& Tsang BK 2002 Nuclear factor kappaB-mediated induction of Flice-like inhibitory protein prevents tumor necrosis factor alpha-induced apoptosis in rat granulosa cells. Biology of Reproduction 67 436-441.

Received 20 October 2006

First decision 1 December 2006

Accepted 1 December 2006 